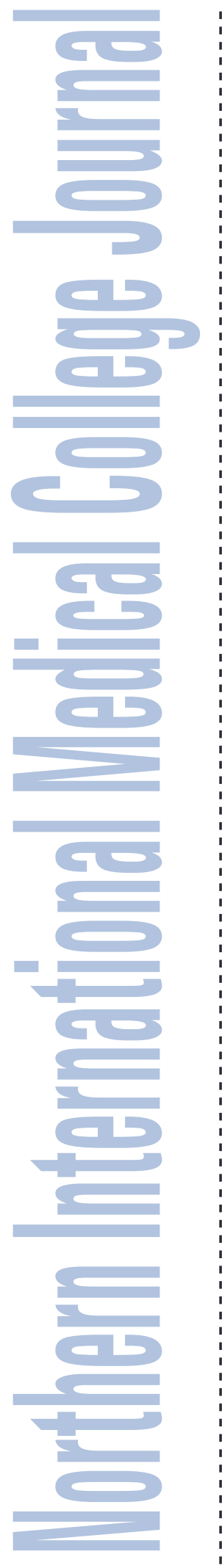

\title{
From the desk of Editor
}

\author{
a success story - a milestone
}

Congratulations to our readers, authors, reviewers and all who have supported us in our endeavor to make a dream in reality-publishing Northern International Medical College J ournal regularly for the last 5 years. In august 2009, a seed was sown. With time it grew in to a green young tree with lively leaves and colorful flowers, and seeing the birds and bees around that beautiful tree is always exciting, as I am also a part of it. With great pride and joy we are entering in to the 6th year of publications.

When we started a new peer-reviewed journal we were skeptical of its continuation. With the grace of Almighty Allah, a very cooperative, knowledgeable editorial board has always supported me to overcome all the obstacles I had faced to publish this journal since its initiation.

Till the writing of this editorial we have published 97 submissions. Among them 47 are original research articles, which is a fairly impressive number for a medical journal of our country's context. Our journal has in possession, the recognition from Bangladesh Medical and Dental Council. Its full text is available online athttp://www.banglajol.info/index.php/NI MC]

Recently I myself the editor along with our executive editor attended "Banglajol Editors' Training Workshop" organized by International Network for the Availability of Scientific Publications (INASP) in collaboration with Bangladesh Academy of Sciences. I have in hope that we will improve our journal's quality and its publication to a level that this journal will find a significant and deserving place among all scientific journals of Bangladesh in the near future.

Children are the most important and precious aspects in our lives. In their own special ways children make us visionaries and make our lives more vibrant and meaningful. We are very much delighted to dedicate this inaugural issue of 6th year to our children. Therefore we have selected to publish most of the original research works related to child health in this issue.

Finally I would once again like to thank all the authors, reviewers, readers for their continuous support, assistance and care. Also I would especially like to send my gratitude to the Chairman of Northern International Medical College, Prof. Dr. Abu Yousuf Md. Abdullah for his continuous support in these 5 years of journey till today where we still look forward to the bright road ahead of us. All of our best effort was poured in to the journal, my sincere apologies if it is of any inconvenience.

\section{Dr. B H Nazma Yasmeen}

Editor

Northern International Medical College J ournal 